\title{
The Impact of IFNL4 rs12979860 Polymorphism on Spontaneous Clearance of Hepatitis C; A Case-Control Study
}

\author{
Heidar Sharafi ${ }^{1,2,3}$; Seyed Moayed Alavian ${ }^{1,2}$; Bita Behnava ${ }^{1,2}$; Ali Pouryasin ${ }^{1,3,4}$; Maryam \\ Keshvari ${ }^{1,2,5, *}$ \\ ${ }^{1}$ Iran Hepatitis Network, Tehran, IR Iran \\ ${ }^{2}$ Middle East Liver Disease (MELD) Center, Tehran, IR Iran \\ ${ }^{3}$ Armin Pathobiology Laboratory, Tehran, IR Iran \\ ${ }^{4}$ Department of Genetics, Islamic Azad University-Arsanjan Branch, Arsanjan, IR Iran \\ 5 Blood Transfusion Research Center, High Institute for Research and Education in Transfusion Medicine, Tehran, IR Iran \\ ${ }^{*}$ Corresponding Author: Maryam Keshvari, Blood Transfusion Research Center, High Institute for Research and Education in Transfusion Medicine, Tehran, IR Iran. Tel:+98-2188601501, \\ Fax:+98-2166900386, E-mail: m.keshvari@ibto.ir
}

Received: August 9, 2014; Revised: September 8, 2014; Accepted: September 8, 2014

\begin{abstract}
Background: About 30\% of individuals with hepatitis C virus (HCV) infection are able to clear HCV spontaneously. Differences in host genetics affect the outcome of HCV infection. Single nucleotide polymorphisms (SNPs) of the Interferon lambda (IFNL) genes were associated with spontaneous and treatment-induced clearance of HCV infection.

Objectives: The aim of this study was to evaluate the association between the IFNL4 rs12979860 SNP and spontaneous clearance of HCV infection in Iranian population.

Materials and Methods: A case-control study was designed on 91 cases with spontaneous HCV infection clearance and 259 patients with persistent HCV infection as the control group. The rs12979860 SNP was assessed as the most common IFNL polymorphism by PCR-RFLP method.

Results: Distribution of rs12979860 CC genotype in the spontaneous clearance group was around two folds of its distribution in chronic hepatitis $\mathrm{C}$ group $(\mathrm{P}<0.001, \mathrm{OR}=4.09,95 \% \mathrm{CI}=2.44-6.86)$.

Conclusions: The rs12979860 SNP was observed as a strong host genetic factor associated with spontaneous clearance of hepatitis C infection.

Keywords: Genetic polymorphism; Hepatitis C; Human IFNL4 Protein
\end{abstract}

\section{Background}

Hepatitis $\mathrm{C}$ is a global health problem. According to the World Health Organization (WHO) estimation, about 170 million patients with hepatitis $\mathrm{C}$ virus (HCV) infection live in the world. Around 70 percent of patients with HCV infection develop chronic hepatitis, which $30 \%$ of them progress to end stage liver disease (1). Approximately $30 \%$ of HCV-infected individuals resolve infection spontaneously and the remaining progress to chronic hepatitis $\mathrm{C}$ (CHC) $(2,3)$. Acute hepatitis C (AHC) can be presented by acute hepatitis presentation such as jaundice and liver enzymes elevation, but most patients spend this phase without any symptoms and as a result, diagnosis in this phase is difficult. According to different studies, viral and host factors have been associated with HCV spontaneous and treatment-related clearance $(4,5)$. Several genomewide association studies (GWAS) demonstrated that rs12979860 single nucleotide polymorphism (SNP) in the intron 1 of Interferon lambda 4 (IFNL4) gene was associated with treatment response in patients with chronic HCV infection (6-8). Previously, rs12979860 SNP was recognized as the polymorphism of IL28B gene (6). Interferon lambda genes located on chromosome 19 belong to the family of type III Interferons. Different interferon lambdas are recognized including IFNL1 (IL29), IFNL2 (IL28A), IFNL3 (IL28B), and IFNL4, which all have been demonstrated to possess antiviral activity in-vivo and in-vitro (9). Different studies showed that the rs12979860 C allele favors response to antiviral treatment of chronic HCV infection $(10,11)$. Frequency of $C$ allele varies in different ethnicities and it was shown to be higher in Caucasians than Africans (4). There is little data regarding the impact of host genetics on spontaneous clearance (SC) of acute hepatitis $\mathrm{C}$ from Iran and the Middle East countries.

\section{Objectives}

The aim of the present study was to identify the impact of rs12979860 SNP on spontaneous clearance of hepatitis C infection.

\section{Materials and Methods}

\subsection{Study Population}

To address directly the role of the rs12979860 SNP on

Copyright (c) 2014, Kowsar Corp.; Published by Kowsar. This is an open-access article distributed under the terms of the Creative Commons Attribution-NonCommercial 4.0 International License (http://creativecommons.org/licenses/by-nc/4.0/) which permits copy and redistribute the material just in noncommercial usages, provided the original work is properly cited. 
HCV spontaneous clearance (SC), we designed a casecontrol study on 91 patients with spontaneous HCV clearance and 259 ones with persistent HCV infection as the case and control groups, respectively. The included individuals all had positive result for anti-HCV antibody (anti-HCVAb) and referred to Tehran Blood Transfusion Hepatitis Clinic from 2011 to 2013. All HCV SC and CHC cases did not receive antiviral therapy for hepatitis $C$ infection before including in the study. The case and control groups were matched regarding sex and age. Patients with coinfection of hepatitis B virus and human immunodeficiency virus were excluded from the study. HCV SC condition was confirmed by anti-HCVAb positivity and subsequent two negative HCV RNA tests by a minimum of 6-month interval; whereas, persistence of HCV RNA in serum more than six months in the presence of anti-HCVAb was considered as CHC. A questionnaire consisted of demographic data and HCV-related risk factors were filled for every patient. All study participants provided informed consent and the study design was approved by the Ethics Committee of Iranian Blood Transfusion Organization. The study protocol conforms to the ethical guidelines of the 1975 declaration of Helsinki.

\subsection{Virological Assessments}

Anti-HCVAb was assessed using Elecsys ${ }^{\circledR}$ Anti-HCV II assay (Roche Diagnostics). Furthermore, HCV RNA in serum was assessed using COBAS $^{\circledR}$ TaqMan ${ }^{\circledR}$ HCV Test v2.0 (Roche Diagnostics) according to the manufacturer's instructions. For HCV genotyping, the core gene of HCV was amplified by QIAGEN OneStep RT-PCR Kit(Qiagen, Hilden, Germany) followed by direct DNA sequencing procedure and phylogenetic analysis.

\subsection{Genotyping of rs12979860 SNP}

In this study, rs12979860 SNP was assessed as the most common IFNL polymorphism. The detailed protocol of polymerase chain reaction-restriction fragment length polymorphism (PCR-RFLP) method for genotyping of rs12979860 SNP was previously described (12). Genomic DNA was extracted from peripheral blood specimen using QIAamp ${ }^{\circledR}$ DNA Blood Mini Kit (Qiagen, Hilden, Germany) according to the manufacturer's instructions. The extracted DNA was amplified using following primers for rs12979860 SNP: 5'-GCGGAAGGAGCAGTTGCGCT-3' and 5'-GGGGCTTTGCTGGGGGAGTG-3'. The temperature profile was consisted of $94^{\circ} \mathrm{C}$ for five minutes; followed by 35 cycles of $94^{\circ} \mathrm{C}$ for 20 seconds, $66^{\circ} \mathrm{C}$ for 20 seconds and $72^{\circ} \mathrm{C}$ for 20 seconds, followed by $72^{\circ} \mathrm{C}$ for five minutes. The PCR product of rs12979860 SNP was digested with Bsh1236I (BstUI) restriction endonuclease (Fermentas, Vilnius, Lithuania) which resulted in two 196 and 45 bp fragments in rs12979860 CC genotype, three 241,196, and $45 \mathrm{bp}$ fragments in rs12979860 CT genotype and a $241 \mathrm{bp}$ fragment in TT genotype.

\subsection{Statistical Analysis}

Categorical variables were expressed by frequency and percentage. Continuous variables were expressed by mean \pm standard deviation (SD). Comparison between categorical variables was performed using Fisher-exact test. P value below 0.05 was considered statistically significant. All statistical analyses were performed using SPSS software for Windows (SPSS, version 17).

\section{Results}

In this case-control study, 350 patients with positive result for anti-HCVAb were included. The mean \pm SD age of the study population was $39.7 \pm 10.4$. Intravenous drug use (IDU) and non-IDU were the main HCV acquiring risk factors among our patients. We could not identify HCV genotypes in SC group because all of them referred after HCV clearance. HCV genotyping revealed HCV genotype 1 as the predominant genotype in patients with $\mathrm{CHC}$ followed by HCV genotype 3. The patients' characteristics are summarized in Table 1 . Among the SC cases, distribution of rs12979860 genotypes was as follows: 64 (70.3\%) were CC, 26 (28.6\%) were CT and 1 (1.1\%) was TT, while among CHC patients, 95 (36.7\%) were CC, 134 (51.7\%) were CT and $30(11.6 \%)$ were TT $(\mathrm{P}<0.001)$ (Figure 1$)$. In the dominant model (CC vs. CT+TT), the distribution of CC genotype in the SC group was around two folds of its distribution in the CHC group $(\mathrm{P}<0.001, \mathrm{OR}=4.09,95 \% \mathrm{CI}=2.44$ 6.86). Moreover, in the allelic model, the frequency of rs12979860 C allele was higher in SC group than the CHC group $(\mathrm{P}<0.001)$ (Table 2$)$.

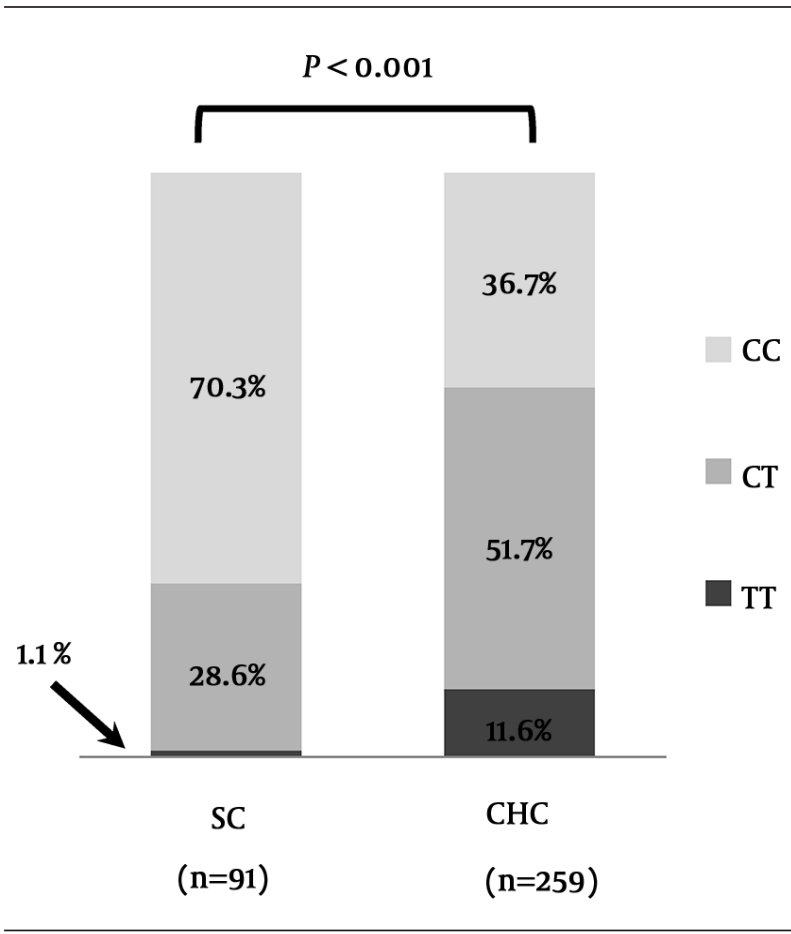

Figure 1. Distribution of rs12979860 Genotypes in SC and CHC Groups 


\begin{tabular}{|c|c|c|}
\hline & $\operatorname{SC}(\mathbf{n}=91)$ & $\mathrm{CHC}(\mathbf{n}=\mathbf{2 5 9})$ \\
\hline \multicolumn{3}{|l|}{ Gender } \\
\hline Male & $87(95.6)$ & $246(95.0)$ \\
\hline Female & $4(4.4)$ & $13(5.0)$ \\
\hline Age, $y$ & $39.2 \pm 11.1$ & $39.8 \pm 10.1$ \\
\hline \multicolumn{3}{|l|}{ HCV genotype } \\
\hline HCV-1 & NA & $140(54.1)$ \\
\hline HCV-3 & NA & $119(45.9)$ \\
\hline \multicolumn{3}{|l|}{ Suspected source of infection } \\
\hline History of cupping & $38(41.8)$ & $138(53.3)$ \\
\hline History of non-IDU & $62(68.1)$ & $200(77.2)$ \\
\hline History of IDU & $56(61.5)$ & $174(67.2)$ \\
\hline History of extramarital sex & $31(34.1)$ & $91(35.1)$ \\
\hline History of imprisonment & $30(33.0)$ & $124(47.9)$ \\
\hline History of tattooing & $29(31.9)$ & $113(43.6)$ \\
\hline
\end{tabular}

a Abbreviations: SC, spontaneous clearance; $\mathrm{CHC}$, chronic hepatitis $\mathrm{C} ; \mathrm{n}$, number; NA, not applicable; IDU, intravenous drug use.

$\mathrm{b}$ Data are presented as No. (\%) or Mean \pm SD.

Table 2. IFNL4 rs12979860 SNP and Spontaneous Clearance of Hepatitis $\mathrm{C}^{\mathrm{a}, \mathrm{b}}$

\begin{tabular}{lccccc}
\hline & $\begin{array}{c}\text { SC } \\
(\mathbf{n}=\mathbf{9 1})\end{array}$ & $\begin{array}{c}\text { CHC } \\
(\mathbf{n}=\mathbf{2 5 9})\end{array}$ & OR & 95\%CI & P Value $^{\mathrm{C}}$ \\
\hline $\begin{array}{l}\text { rs12979860 } \\
\text { genotypes }\end{array}$ & & & & & \\
\multicolumn{1}{c}{ Non-CC } & $27(29.7)$ & $164(63.3)$ & Reference & & \\
CC & $64(70.3)$ & $95(36.7)$ & 4.09 & $2.44-6.86$ & $<0.001$ \\
rs12979860 & & & & & \\
alleles & & & & & \\
\hline$T$ & $28(15.4)$ & $194(37.5)$ & & & \\
C & $154(84.6)$ & $324(62.5)$ & & & $<0.001$ \\
\hline
\end{tabular}

a Abbreviations: SC, spontaneous clearance; $\mathrm{CHC}$, chronic hepatitis C; OR, odds ratio; $\mathrm{CI}$, confidence interval; $\mathrm{n}$, number.

$\mathrm{b}$ Data are presented as No. (\%).

${ }^{\mathrm{c}}$ Fisher-exact test.

\section{Discussion}

The present study investigated the impact of a genetic variant (rs12979860) in a gene (IFNL4) involving in host innate immunity on HCV SC. rs12979860 SNP had a significant association with SC of HCV infection in our study. In addition, distribution of rs12979860 genotypes among patients with CHC was $36.7 \%, 51.7 \%$, and $11.6 \%$ for CC, CT, and TT genotypes, respectively, which was similar to the distribution of rs12979860 genotypes investigated in Iranian patients with CHC previously (13). First studies that reported the association between IL28B SNPs and HCV infection obtained from large cohorts of patients with chronic HCV infection who received standard antiviral treatment $(7,8)$. An Egyptian study found that individu- als with HCV SC were about three times more likely to have rs12979860 CC genotype than those with CHC (14). Another study from Egypt reported that the frequency of IL28B CC genotype was significantly higher in the HCV SC group than healthy individuals, CHC patients, and cases with HCV-related liver cirrhosis and hepatocellular carcinoma (15). In the study by Montes-Cano et al. (16) among 352 HCV-infected Spanish cases, rs12979860 CC genotype was associated with a higher rate of HCV SC in both men $(72.4 \%$ in CC vs. $27.6 \%$ in non-CC) and women $(72.5 \%$ in CC vs. $27.5 \%$ in non-CC). In a study from Austria, IL28B rs12979860 CC genotype was more frequent among patients with HCV SC than those with CT and TT genotypes (17). In the study by Grebely et al. (18) among 132 Australians, rs8099917 TT genotype was the only factor predicting HCV SC in multivariate analysis. According to a metaanalysis, IL28B rs12979860 CC and rs8099917 TT genotypes were associated with HCV SC in Caucasians (19). The mechanism in which the IL28B SNPs result in inter-individual differences in HCVSC is not well understood. However, few studies looked for different levels of IFNL3 and interferon-stimulated genes by different IL28B genotypes, but obtained results were inconsistent and affected by different study settings (7, 8, 20-22). Prokunina-Olsson et al. reported the presence and expression of a gene named IFNL4 (23). The exon one of the recently discovered IFNL gene contained a genetic variant (ss469415590), which was associated with expression of the IFNL4 peptide (23). Interestingly, the TT allele of ss469415590 does not express the IFNL4 peptide and was associated with SC of $\mathrm{HCV}$, while the $\Delta \mathrm{G}$ allele of ss 469415590 expresses a functional peptide of IFNL4 and was associated with chronicity of HCV infection (23). Besides, it was observed that ss469415590 is in high linkage disequilibrium (LD) with rs12979860 in Caucasians $(24,25)$. Discovery of IFNL4 gene and the association of ss469415590 with the outcome of $\mathrm{HCV}$ infection has opened new horizons in diagnosis and management of hepatitis $C$ in near future. A recent study recommended that patients with AHC and unfavorable IL28B genotypes should be treated with antiviral drugs rapidly (18). One percent of our study population who cleared HCV had TT genotype, thus antiviral therapy in patients with AHC and rs12979860 TT genotype seems to be advisable. Other studies found that patients with an icteric AHC had a higher chance to clear virus spontaneously $(26,27)$. Tillman et al. (10) observed that $52 \%$ of patients with symptomatic AHC cleared the infection spontaneously, whereas none of the patients with asymptomatic AHC cleared HCV RNA without antiviral treatment, therefore they recommended to treat asymptomatic AHC patients as early as possible. Other finding in AHC was the higher frequency of IL28B rs12979860 CC genotype in patients with icteric AHC than those without AHC symptoms (10). Recently, Interferon gamma inducible protein 10 (IP-10), which is a chemotactic chemokine has been introduced as a pretreatment predictive factor in $\mathrm{CHC}$ outcome. Beinhardt et al. (17) observed that combination of 
serum level of IP-10 and IL28B SNPs can identify patients with AHC who are most likely to undergo HCV SC and those who progress to $\mathrm{CHC}$ and need early antiviral treatment. They found that IP-10 level was lower in patients who cleared HCV spontaneously (17). Gender had a great influence among factors affecting AHC outcome, which female patients had more chance for achieving HCV SC than the males (28). The study by van den Berg et al. (29) showed that SC status was more frequent in females with the favorable genotype for rs12979860 (CC) than females with the unfavorable genotypes (CT and TT). Several studies have shown that female gender and symptomatic acute hepatitis $C$ were highly associated with HCV SC (30). A recent study in patients with acute HCV genotype 4 infection identified that IL28B CC genotype, female sex, robust T-cell responses, rapid decline in ALT and HCV RNA levels, and presence of jaundice were predictors of HCV SC (31). HCV genotype was another factor able to predict the outcome of AHC. According to the study by Grebely et al. (32) patients with HCV genotype 1 cleared HCV more frequently than those with other HCV genotypes. The route of $\mathrm{HCV}$ transmission may affect AHC outcome as well. A large population cohort study in the northeast of Iran showed that illicit drug use whether intravenous or non-intravenous was significantly correlated with $\mathrm{CHC}$ versus HCV SC. The rate of HCV SC in this study was about $38 \%$ (33). Grebely et al. (34) found that the rate of HCV SC was lower in illicit drug use and HIV coinfection. Shores et al. (35) observed that the rate of HCV SC in HIV-infected patients who acquired HCV from intravenous drug use was significantly lower than those with sexual transmission as the presumed route of HCV transmission. In addition, it was observed that the rate of HCV SC was up to 50\% in children and women infected after $\mathrm{RH}$ immunization $(28,36)$. In the present study, all SC cases were included after HCV clearance, thus determination of HCV RNA level and HCV genotyping were impossible.

In conclusion, the present study confirmed the role of host immunity on outcome of viral infection by investigating the impact of IFNL4 rs12979860 SNP on natural history of HCV infection. More large-scale multicentric longitudinal studies are needed to reliably evaluate the outcome of patients in acute hepatitis $\mathrm{C}$ phase regarding different host and viral factors.

\section{Acknowledgements}

We gratefully acknowledge The Hepatitis Clinic of Tehran Blood Transfusion Center and Middle East Liver Disease (MELD) Center staff. Furthermore, we would like to thank Dr. Kalhor Zadeh for her assistance in data collection.

\section{Authors' Contributions}

Seyed Moayed Alavian, Bita Behnava and Maryam Keshvari: designed the study and contributed in sample collection; Heidar Sharafi and Ali Pouryasin: performed the study; Heidar Sharafi and Maryam Keshvari analyzed the data and wrote the paper.

\section{Funding/Support}

This study was supported by Armin Pathobiology Laboratory.

\section{References}

1. Thomas DL, Seeff LB. Natural history of hepatitis C. Clin Liver Dis. 2005;9(3):383-98.

2. Kamal SM. Acute hepatitis C: a systematic review. Am J Gastroenterol. 2008;103(5):1283-97.

3. Thomas DL, Astemborski J, Rai RM, Anania FA, Schaeffer M, Galai $\mathrm{N}$, et al. The natural history of hepatitis $\mathrm{C}$ virus infection: host, viral, and environmental factors. JAMA. 2000;284(4):450-6.

4. Thomas DL, Thio CL, Martin MP, Qi Y, Ge D, O'Huigin C, et al. Genetic variation in IL28B and spontaneous clearance of hepatitis C virus. Nature. 2009;461(7265):798-801.

5. Shi X, Pan Y, Wang M, Wang D, Li W, Jiang T, et al. IL28B genetic variation is associated with spontaneous clearance of hepatitis $\mathrm{C}$ virus, treatment response, serum IL-28B levels in Chinese population. PLoS One. 2012;7(5).

6. Ge D, Fellay J, Thompson AJ, Simon JS, Shianna KV, Urban TJ, et al. Genetic variation in IL28B predicts hepatitis C treatment-induced viral clearance. Nature. 2009;461(7262):399-401.

7. Tanaka Y, Nishida N, Sugiyama M, Kurosaki M, Matsuura K, Sakamoto N, et al. Genome-wide association of IL28B with response to pegylated interferon-alpha and ribavirin therapy for chronic hepatitis C. Nat Genet. 2009;41(10):1105-9.

8. Suppiah V, Moldovan M, Ahlenstiel G, Berg T, Weltman M, Abate ML, et al. IL28B is associated with response to chronic hepatitis C interferon-alpha and ribavirin therapy. Nat Genet. 2009;41(10):1100-4.

9. Galmozzi E, Vigano M, Lampertico P. Systematic review with meta-analysis: do interferon lambda 3 polymorphisms predict the outcome of interferon-therapy in hepatitis B infection? Aliment Pharmacol Ther. 2014;39(6):569-78.

10. Tillmann HL, Thompson AJ, Patel K, Wiese M, Tenckhoff H, Nischalke HD, et al. A polymorphism near IL28B is associated with spontaneous clearance of acute hepatitis $C$ virus and jaundice. Gastroenterology. 2010;139(5):1586-92.

11. Ruiz-Extremera A, Munoz-Gamez JA, Salmeron-Ruiz MA, de Rueda PM, Quiles-Perez R, Gila-Medina A, et al. Genetic variation in interleukin $28 \mathrm{~B}$ with respect to vertical transmission of hepatitis $\mathrm{C}$ virus and spontaneous clearance in HCV-infected children. Hepatology. 2011;53(6):1830-8.

12. Sharafi H, Pouryasin A, Alavian SM, Behnava B, Keshvari M, Mehrnoush L, et al. Development and Validation of a Simple, Rapid and Inexpensive PCR-RFLP Method for Genotyping of Common IL28B Polymorphisms: A Useful Pharmacogenetic Tool for Prediction of Hepatitis C Treatment Response. Hepat Mon. 2012;12(3):190-5.

13. Sharafi H, Pouryasin A, Alavian SM, Behnava B, Keshvari M, Salimi S, et al. Distribution of IL28B Genotypes in Iranian Patients with Chronic Hepatitis C and Healthy Individuals. Hepat Mon. 2012;12(12).

14. Kurbanov F, Abdel-Hamid M, Latanich R, Astemborski J, Mohamed M, Mikhail NM, et al. Genetic polymorphism in IL28B is associated with spontaneous clearance of hepatitis C virus genotype 4 infection in an Egyptian cohort. J Infect Dis. 2011;204(9):1391-4.

15. El-Awady MK, Mostafa L, Tabll AA, Abdelhafez TH, Bader El Din NG Zayed N, et al. Association of IL28B SNP With Progression of Egyptian HCV Genotype 4 Patients to End Stage Liver Disease. Hepat Mon. 2012;12(4):271-7.

16. Montes-Cano MA, Garcia-Lozano JR, Abad-Molina C, Romero-Gomez M, Barroso N, Aguilar-Reina J, et al. Interleukin-28B genetic variants and hepatitis virus infection by different viral genotypes. Hepatology. 2010;52(1):33-7. 
17. Beinhardt S, Aberle JH, Strasser M, Dulic-Lakovic E, Maieron A Kreil A, et al. Serum level of IP-10 increases predictive value of IL28B polymorphisms for spontaneous clearance of acute HCV infection. Gastroenterology. 2012;142(1):78-85 e2.

18. Grebely J, Petoumenos K, Hellard M, Matthews GV, Suppiah V, Applegate T, et al. Potential role for interleukin-28B genotype in treatment decision-making in recent hepatitis $\mathrm{C}$ virus infection. Hepatology. 2010;52(4):1216-24.

19. Zheng MH, Li Y, Xiao DD, Shi KQ, Fan YC, Chen LL, et al. Interleukin-28B rs12979860C/T and rs8099917T/G contribute to spontaneous clearance of hepatitis $\mathrm{C}$ virus in Caucasians. Gene. 2013;518(2):479-82.

20. Raglow Z, Thoma-Perry C, Gilroy R, Wan YJ. IL28B genotype and the expression of ISGs in normal liver. Liver Int. 2013;33(7):991-8.

21. Abe H, Hayes CN, Ochi H, Maekawa T, Tsuge M, Miki D, et al. IL28 variation affects expression of interferon stimulated genes and peg-interferon and ribavirin therapy. J Hepatol. 2011; 54(6):1094-101.

22. Honda M, Sakai A, Yamashita T, Nakamoto Y, Mizukoshi E, Sakai Y, et al. Hepatic ISG expression is associated with genetic variation in interleukin 28B and the outcome of IFN therapy for chronic hepatitis C. Gastroenterology. 2010;139(2):499-509.

23. Prokunina-Olsson L, Muchmore B, Tang W, Pfeiffer RM, Park H, Dickensheets $\mathrm{H}$, et al. A variant upstream of IFNL3 (IL28B) creating a new interferon gene IFNL4 is associated with impaired clearance of hepatitis C virus. Nat Genet. 2013;45(2):164-71.

24. Stattermayer AF, Strassl R, Maieron A, Rutter K, Stauber R, Strasser $\mathrm{M}$, et al. Polymorphisms of interferon-lambda4 and IL28B - effects on treatment response to interferon/ribavirin in patients with chronic hepatitis C. Aliment Pharmacol Ther. 2014; 39(1):104-11.

25. Keshvari M, Pouryasin A, Behnava B, Sharafi H, Hajarizadeh B, Alavian SM. Letter: the rs12979860 and ss469415590 polymorphisms of IFNL4 gene are in strong linkage disequilibrium in Caucasian patients with chronic hepatitis C. Aliment Pharmacol Ther. 2014;39(3):343.

26. Hofer H, Watkins-Riedel T, Janata O, Penner E, Holzmann H, Steindl-Munda P, et al. Spontaneous viral clearance in patients with acute hepatitis $C$ can be predicted by repeated measurements of serum viral load. Hepatology. 2003;37(1):60-4.

27. Gerlach JT, Diepolder HM, Zachoval R, Gruener NH, Jung MC Ulsenheimer A, et al. Acute hepatitis C: high rate of both spontaneous and treatment-induced viral clearance. Gastroenterology. 2003;125(1):80-8.

28. Kenny-Walsh E. Clinical outcomes after hepatitis $C$ infection from contaminated anti-D immune globulin. Irish Hepatology Research Group. NEngl J Med.1999;340(16):1228-33.

29. van den Berg CH, Grady BP, Schinkel J, van de Laar T, Molenkamp R, van Houdt R, et al. Female sex and IL28B, a synergism for spontaneous viral clearance in hepatitis $C$ virus (HCV) seroconverters from a community-based cohort. PLoS One. 2011;6(11).

30. Micallef JM, Kaldor JM, Dore GJ. Spontaneous viral clearance following acute hepatitis $C$ infection: a systematic review of longitudinal studies. J Viral Hepat. 2006;13(1):34-41.

31. Kamal SM, Kassim SK, Ahmed AI, Mahmoud S, Bahnasy KA, Hafez TA, et al. Host and viral determinants of the outcome of exposure to HCV infection genotype 4: a large longitudinal study. Am J Gastroenterol. 2014;109(2):199-211.

32. Grebely J, Page K, Sacks-Davis R, van der Loeff MS, Rice TM, Bruneau J, et al. The effects of female sex, viral genotype, and IL28B genotype on spontaneous clearance of acute hepatitis $\mathrm{C}$ virus infection. Hepatology. 2014;59(1):109-20.

33. Poustchi H, Esmaili S, Mohamadkhani A, Nikmahzar A, Pourshams A, Sepanlou SG, et al. The impact of illicit drug use on spontaneous hepatitis C clearance: experience from a large cohort population study. PLoS One. 2011;6(8).

34. Grebely J, Raffa JD, Lai C, Krajden M, Conway B, Tyndall MW. Factors associated with spontaneous clearance of hepatitis $C$ virus among illicit drug users. Can J Gastroenterol. 2007;21(7):447-51.

35. Shores NJ, Maida I, Soriano V, Nunez M. Sexual transmission is associated with spontaneous HCV clearance in HIV-infected patients. J Hepatol. 2008;49(3):323-8.

36. Wiese M, Grungreiff K, Guthoff W, Lafrenz M, Oesen U, Porst $\mathrm{H}$, et al. Outcome in a hepatitis $\mathrm{C}$ (genotype $1 \mathrm{~b}$ ) single source outbreak in Germany-a 25-year multicenter study. $J$ Hepatol. 2005;43(4):590-8. 